\title{
IRONIA COMO RECURSO DO DISCURSO POLÍTICO DOS USUÁRIOS DE MÍDIAS SOCIAIS: PRIMEIRAS ANÁLISES ACERCA DO CASO MYRIAN RIOS
}

\author{
Luiz Cláudio Kleaim ${ }^{45}$ \\ Sérgio Rodrigo da Silva Ferreira ${ }^{46}$
}

\section{IRONY AS A RHETORICAL DEVICE OF THE POLITICAL DISCOURSE OF SOCIAL MEDIA USERS: FIRST REVIEW ABOUT THE CASE MYRIAN RIOS}

\section{Resumo}

A ironia é um recurso estilístico da linguagem associado à ideia de oposição e contradição. $\mathrm{O}$ objetivo deste estudo de caso é refletir sobre a questão do uso desse estilo nos discursos de usuários de diferentes redes sociais online na internet e seu valor como estratégia política. Usou-se como fonte de dados a repercussão do discurso da deputada Myrian Rios em post de weblog, vídeo do YouTube e textos do site Twitter que possuíam caráter irônico. Os resultados mostram que a ironia nos casos estudados foi utilizada para desacreditar a enunciadora do discurso original e fazer ruir seus argumentos. Concluímos que, num contexto histórico-político em que cresce a importância das redes sociais online na influência da opinião pública, e da opinião pública no fazer político, a estratégia discursiva da ironia tem eficácia iconoclasta e possui riscos devido à necessidade de compartilhamento de contextos entre os interlocutores. Palavras-chave: Internet. Ironia. Política. Redes Sociais.

\section{Abstract}

The irony is a stylistic feature of language with the idea of opposition and contradiction. The objective of this case study is to reflect on the issue

45 Mestre e Licenciado em Letras, pela Universidade Federal do Espírito Santo - UFES, professor da Rede Pública Estadual de Ensino do Espírito Santo, integrante do Plur@I - Grupo de Diversidade Sexual e do GEPSs - Grupo de Estudos e Pesquisas em Sexualidades da UFES. E-mail: luizclaudiokleaim@yahoo.com.br. 
of using the figure of irony in the speeches of users from different online social networks on the Internet and its value as a political strategy. Used as a data source the impact of the speech by Mrs Myriam Rios in a weblog post, YouTube video and text of the Twitter site that had character ironic. The results show that the irony in the case studies was used to discredit the statement of the original speech and make its arguments crumble. We conclude that a political-historical context in which the growing importance of online social networks in influencing public opinion and public opinion in policy making, the discursive strategy of irony is as effective as iconoclastic and risks due to the need for sharing between contexts interlocutors.

Key words: Internet. Irony. Politics. Social Networks.

\section{Introdução}

No dia 21 de junho de 2011, na plenária da Assembleia Legislativa do Estado do Rio de Janeiro, a deputada, e ex-atriz, Myrian Rios (PDT-RJ) proferiu discurso de posicionamento contrário à aprovação da Proposta de Emenda Constitucional (PEC) 23/2007, a qual tornaria crime a prática da homofobia. Segundo tal projeto de emenda, seria acrescentado o termo orientação sexual às modalidades de atos discriminatórios passíveis de punição pelo Estado.

Para arcabouçar seu argumento, a deputada alegou que, caso a proposta fosse aprovada, estaria se privando da igualdade de direitos, pois não mais teria o direito de demitir algum funcionário se descobrisse ser este lésbica ou homossexual. Além de se afirmar como representante do povo, ex-atriz, mãe e missionária católica, a parlamentar, defendendo-se (ora sob discurso religioso, ora sob o artigo quinto da Constituição), buscou associar a homossexualidade à pedofilia. 
Em decorrência disso, seu depoimento alcançou notável repercussão nas mídias sociais ${ }^{47}$, recebendo, sob variadas formas e sob diferentes suportes, respostas de apoio ou de desapreço de diversos setores da sociedade. Entidades, pessoas e movimentos sociais, utilizando-se de cartas públicas, mensagens eletrônicas, vídeos de respostas, tuitaços e outros meios, buscaram transmitir seus desagravos à parlamentar. Dentre essas modalidades de comunicação, foi possível notar em alguns textos de resposta um recurso estilístico de linguagem muito utilizado na política: a ironia.

Atualmente, o crescimento do uso da internet e das redes sociais online torna esses veículos não só uma importante fonte de informação alternativa à das grandes empresas de comunicação para seus usuários, mas também permite que atuem como produtores e divulgadores de notícias, além de emissores de opiniões sobre os fatos, suplantando o modelo tradicional da comunicação massiva de caráter unilateralista - que, com sua falsa ilusão de onipresença, há tempos vem fazendo a mediação entre a realidade política, econômica, cultural - por um outro mais rizomático, dado seu modo colaborativo e pró-ativo de ser, trazendo à tona outros pontos de vista dessa "realidade". Observada essa transformação, percebemos que também mudou a relação de influência da opinião pública, pois os relatos se tornam mais um ponto de tensão que a empurra em múltiplas direções, evidenciando o aspecto político das redes sociais. Justifica-se, pois, este trabalho, na necessidade de explorar o uso atual de tais redes e as estratégias de comunicação em seu viés político a fim de se criarem bases a estudos futuros sobre o tema, além de testar as teorias já existentes sobre o assunto.

O objetivo deste estudo de caso é, portanto, o de refletir sobre a questão do uso da figura da ironia nos discursos de usuários de diferentes redes sociais online na internet e seu valor como estratégia política de resistência ou de contrariedade, focando-se em um determinado fato irradiador - 0 discurso da deputada Myrian Rios contra a emenda PEC 23 -, a partir da bibliografia sobre o tema. Neste trabalho, discurso será definido de forma geral a partir da perspectiva foucaultiana (FISCHER, 2001, p. 198), como sendo uma prática social presente no nível das coisas ditas e não ditas, das 
palavras, do praticado e do silenciado, cabendo ao interpretante apreender sua complexidade e dar conta de suas relações históricas e políticas.

\section{Contexto}

O contexto histórico hodierno em que os suportes das mediações semióticas analisadas se inscrevem é o que Negri e Hardt, em seu livro Império, afirmam ser o terceiro momento de uma sucessão de paradigmas econômicos que se definem pelo setor que domina a economia num dado período histórico: a manipulação da informação, das linguagens e dos meios. Os dois momentos anteriores estavam baseados o primeiro em uma economia agrícola e extrativista de matérias-primas, e o segundo em uma economia dominada pela indústria e pela fabricação de bens duráveis. Estes dois últimos momentos contrastam com o terceiro - e atual - paradigma, segundo o qual a oferta de serviços e o manuseio de informações estão no cerne da produção econômica (HARDT; NEGRI, 2001).

Os processos de informatização da produção que têm ocorrido desde o início do período pós-industrial acarretaram uma série de transformações que redefiniram grande parte dos elementos do plano social, como afirmam os autores. A mercadoria de maior valor tornou-se a informação e, por isso, a estrutura e a administração das redes de comunicação - embutidas nos novos processos de produção e que lhes são totalmente inerentes - são condições essenciais para a produção da economia informacional.

Essas mudanças históricas não só se referem aos paradigmas econômicos, mas também a toda uma multiplicidade de fatores de organização social, política, familiar, moral etc. A Internet, como uma das principais novas tecnologias da informação, tornou-se uma das engrenagens fundamentais desse período, sendo caracterizada, inicialmente, como um conglomerado de redes em escala mundial de milhões de computadores, que funcionam como superestradas da informação. Há de se observar que o modo em que se estrutura essa rede possui a lógica rizomática, modelo teórico desenvolvido por Deleuze e Guatarri que a caracteriza como um sistema "a-centrado não hierárquico e não significante, sem General, sem memória organizadora 
ou autômato central, unicamente definido por uma circulação de estados", como "um mapa que deve ser produzido, construído, sempre desmontável, conectável, reversível, modificável, com múltiplas entradas e saídas, com suas linhas de fuga" (DELEUZE; GUATARRI, 2004). Ou seja, nenhum ponto da rede é necessário para que os outros pontos se comuniquem; o que faz da Internet um sistema difícil de regulamentar e de se coibir o trânsito das informações, trazendo em si um devir democratizador ou mesmo anárquico. Lévy (1999) afirma que quanto mais essa rede se amplia, mais ela se torna "universal" e "menos o mundo informacional se torna 'totalizante". Já que não possui centro nem linha diretriz e ser vazia e sem conteúdo particular, a rede aceita a todos como produtores ou emissores de novas informações.

Para Santaella (2008), o cerne desse período, chamado por ela de revolução digital - dado o impacto que a explosão dos meios de reprodução técnico-industriais teve na cultura ainda no século $X X$-, está nas possibilidades que as novas tecnologias dão de converter toda informação (texto, som, imagem, vídeo etc.) em uma mesma linguagem universal por meio da digitalização e da compressão de dados, podendo ser traduzidos, manipulados, armazenados, reproduzidos e distribuídos; fenômeno esse chamado de convergência de mídias. O resultado disso são cruzamentos culturais que conectam todo o globo na constituição de novas formas de socialização e de cultura, num processo galopante de dissolução das fronteiras entre alta e baixa cultura, da grande mídia e do relato do indivíduo comum.

\section{A ironia e as vozes (contraditórias) dentro do discurso}

A noção de ironia é mencionada em diversos meios e situações. Comumente se caracteriza como recurso estilístico importante na linguagem associado à ideia de oposição. Seu significado, segundo o Dicionário Houaiss, é:

1. (Rubrica: retórica) figura por meio da qual se diz o contrário do que se quer dar a entender; uso de palavra ou frase de sentido diverso ou oposto ao que deveria ser empr., para definir ou denominar algo [A ironia ressalta do contexto. 
1.1. (Rubrica: literatura) esta figura, caracterizada pelo emprego inteligente de contrastes, us. literariamente para criar ou ressaltar certos efeitos humorísticos

2. m.q. asteísmo ('uso sutil')

3. uso de palavra ou expressão sarcástica; qualquer comentário ou afirmação irônica ou sarcástica; 4. (Derivação: sentido figurado) contraste ou incongruência que se afigura como sarcasmo ou troça; acontecimento marcado por esse contraste ou incongruência Ex.: as i. da vida, do destino

Observando o campo semântico das palavras compostas com o morfema iron-, o sentido de ironia provém

do gr. eiróneía,as 'ação de interrogar fingindo não saber; dissimulação, reticência', der. do $v$. eiróneúomai 'fingir-se de ignorante, de ingênuo; dissimular, fingir', pelo lat. ironía, ae 'ironia, figura de retórica'; ocorre em vocábulos doc. na língua a partir do sXV: ironia, irônico, ironismo, ironista, ironização, ironizado, ironizador, ironizante, ironizar, ironizável.

Haraway (2009, p. 35) diz que a ironia constitui estratégia retórica importante para o embate político. Ela está relacionada a "contradições que não se resolvem - ainda que dialeticamente - em totalidades mais amplas: ela tem a ver com a tensão de manter juntas coisas incompatíveis porque todas são necessárias e verdadeiras. A ironia tem a ver com o humor e o jogo sério", completa a pensadora.

De acordo com Facioli (2010, p. 22-23), pensar a ironia apenas como um discurso que representaria o contrário impedir-nos-ia de observar

O desenrolar de toda uma garra de derivações possíveis da posição irônica ao restringi-la a um campo de manifestações portadoras de uma proposta retórica cosmética, vazia no que pode implicar-se enquanto um fenômeno catalisador de recriações no plano da comunicação e interação humanas. 
Segundo o autor, "o ironista não somente enuncia ironia, ornamentando seu discurso com a mesma, mas também se vincula ao outro segundo parâmetros delineados por sua forma" (FACIOLI, 2010, p. 23). Nesse sentido, ele "deve ser capaz de sustentar contrariedade, contradição ou ambivalência. Para sustentar uma posição contrária à própria é necessário um espírito dramático: ironizar possui grandes afinidades com o dramatizar" (FACIOLI, 2010, p. 23). Para seu desenlace, a ironia requer a simulação e o movimento hipotético "de trânsito de papéis, que compõe o drama" (FACIOLI, 2010, p. 23). Entendido assim, o ironista utiliza a realidade para modelá-la, reinventá-la, ou seja, transfigurar ou recriar a realidade. A transgressão de seus textos pode ser encontrada na reapresentação da realidade ou em sua repetição, só que absurda e irreal.

O ironista, muitas vezes, de modo a se opor, retoma o discurso do texto original de forma a simular a afirmação deste, mas provocando outros significados. Nesse aspecto, a ironia contida em seu texto, além de ser observada tradicionalmente como um discurso que se representa ao contrário, muitas vezes se revela por meio de contradição e de ambivalência.

Nascimento (2010), ao fazer a análise do Portal Nosso São Paulo, concluiu que a ironia é um recurso argumentativo que exige do leitor participação ativa no processo de negociação e de interpretação de sentido, no qual o enunciado intencional do autor se recupera na contradição dos valores argumentativos das comunidades ideológicas. Dessa forma, a ironia está na capacidade de manter os valores anteriores aos novos propostos, na percepção da contradição do argumento mesmo sem que o enunciado em sua estrutura gramatical esteja invertido.

\section{Método}

A metodologia adotada neste trabalho observou o paradigma do construtivismo social - combinado com interpretativismo - que, segundo Creswell (2007) afirma, os indivíduos estão sempre buscando entender o mundo em que vivem e, desse modo, criam significados subjetivos para suas experiên- 
cias que são variados e múltiplos. Dessa forma, busca-se a complexidade das visões de mundo dos participantes focando na interpretação dos símbolos e do significado.

Para isso, a pesquisa de caráter qualitativo utilizou como estratégia de investigação o Estudo de Caso, para procurar explorar com profundidade as produções em diferentes suportes online - no caso weblog, Twitter e Youtube - a fim de descrever de que modo o recurso retórico da ironia foi utilizado como estratégia política, analisar os discursos presentes e refletir sobre a intencionalidade e os possíveis resultados sobre os receptores das mensagens, a partir da literatura adotada.

A pesquisa utilizou como objetos de análise documentos em texto, ilustrações e vídeo publicados na internet - e de livre acesso - que referenciavam o discurso anteriormente citado. Fazem parte da análise 1 post em blog, 96 tweets ligados a uma atividade específica proposta por um usuário no Twitter e 1 vídeo, conforme exporemos adiante. Estas produções foram descritas, assim como sua forma de expressão, dentro de cada um dos suportes midiáticos utilizados. Em seguida, procurou-se "separar" os índices que explicitam as figuras de ironia e seu papel em relação ao discurso original. Por fim, foram comparadas as diferentes estratégias, evidenciando possíveis peculiaridades e aproximações. A partir daí, fez-se uma reflexão sobre a função política da ironia desses discursos por meio do diálogo com os autores referenciados.

\section{Resultados}

Analisamos três casos em diferentes suportes midiáticos: vídeo, post em weblog e tweets. No primeiro suporte, o vídeo Myrian Réus ${ }^{48}$, de 3'35", de Celso André, postado no Youtube, no dia 28 de junho de 2011, exibe a parlamentar (um ator travestido de mulher, trajando terno feminino e usando peruca), com uma revista na mão, manifestando seu pronunciamento contrário à aprovação de uma suposta proposta de "remenda". Ao sinal de uma voz off, ela comenta que estava com saudades (“- Tá gravando?! Ai,

48 http://www.youtube.com/watch?v=LAwCKPiRH1I 
eu estava com saudade desta palavra!") da palavra "gravando", saúda o povo e se apresenta como mãe, deputada e ex-atriz para prosseguir com seu argumento (“... quero dizer que eu estou aqui como mãe... e como mãe eu represento uma atriz... E segundamente que eu estou aqui como deputada... e como deputada eu represento uma ex-atriz").

Dessa forma, a personagem se revela identitariamente sob essas três marcações, mas já a partir daí, dois sentidos para a ideia de representação (representar o povo e representar um papel) se confundem e, ao mesmo tempo, tornam ambígua a interpretação. Representar é um verbo associado tanto ao mundo da arte e do teatro, quanto à linguagem jurídica e política. Ao mencionar que está representando, a personagem do texto irônico aproxima o plenário e o palco, confundindo-os e provocando o deslocamento/ descolamento do texto original.

Ao mesmo tempo, demarcando-se como ex-atriz, Myrian Réus confirma desconformidade em sua situação por ocupar um lugar errado. Seu lugar não é na tribuna, é nos palcos. Exibida sua saudade do imperativo das câmeras de tevê ("Gravando!") no início de seu pronunciamento, o restante de sua fala é desmerecido, daí em diante, no decorrer do texto.

Além de sua fala transmitir a ideia de que ela se encontra no lugar errado, a ocorrência inapropriada de certas palavras e de algumas frases demonstra sua fragilidade de intelecto, como se pode ver no emprego de: "remenda", "remenda do colega", "eu fiquei confusa... não entendi direito" ou, ainda, "Eu não tenho o preconceito dentro de mim... assim como também eu não discrimino... eu não tenho o discrimino dentro de mim... não tenho... pode me revistar que eu não tenho".

No decurso do texto irônico, a deputada faz menção à impossibilidade de demitir funcionários, dias depois de descobrir que as orientações sexuais deles são diferentes daquelas da sua casa, caso a lei seja aprovada. Para exemplificar, ela aventa a possibilidade de ter contratado determinadas modalidades de serviço: 1) uma babá cuja orientação sexual é ser gorda; 2) um motorista cuja orientação sexual é ser anão; 3) uma passadeira cuja orientação sexual "é negra... ou é amarela... ou quiçá deficiente". E sugere a influência que essas marcações de diferença ou que essas pessoas poderiam transmitir (essas marcas) para suas crianças (sempre relatadas em 
números de dezenas) em sua casa.

Sabe-se que as marcas de diferença corporal (gordo/magro, alto/anão, deficiente) e de cor (negro/branco/amarelo) não estão relacionadas à sexualidade. Tratam-se de marcações que não são por livre escolha, além de serem aspectos que notamos à primeira vista dessas pessoas. Entretanto, as suposições de Myrian Réus de descoberta dessas características para a demissão dos funcionários só acontecem no segundo (gorda), terceiro (anão) ou quarto dias (negra/amarela/deficiente); fato este que nos leva ao absurdo, à impressão de extrema desatenção da empregadora ou, remetendo ao texto original, de que talvez a orientação sexual não seja algo assim tão à mostra para se descobrir.

Assim, quando a parlamentar retrata esses funcionários com esses signos de diferença enquanto algo pelo que eles optaram, emerge o signo do absurdo e do risível, além de reforçar a recepção da repugnância e do absurdo do texto irônico, tornando Myrian Réus/Myrian Rios impopular, burra, divorciada e com um passado que a condena (ré).

Vale ainda realçar que durante a fala de Myrian Réus, por três vezes ouve-se uma música de Roberto Carlos (ex-marido de Myrian Rios) e ela responde: "Já vou te dar sua parte... Já vou te dar uma parte... já vou te dar uma part...". Ao final do vídeo, na terceira persistência da música, ela se enfurece e diz que não vai dar o aparte, pois já está divorciada. Este trecho remete à situação do texto original em que um deputado pede um aparte com certa insistência e a deputada responde dizendo que já o cederá. Em seguida, ela revida "Hãm,?!... que foi?... Divórcio não pode? ... Mas que preconceito!" e mostra a capa da revista em que posou nua Myrian Rios. E na saída ela suscita o fato de estar toda alérgica, fazendo um trocadilho com as iniciais da Assembleia Legislativa do Rio de Janeiro (Alerj).

O segundo suporte é um texto irônico postado no weblog cleycianne. com, cujo autor é Thiago Pereira, que tem como perfil/personagem uma modelo fotográfica, cristã e batizada, que utiliza o veículo blog para comentar os fatos midiáticos com uma visão cristã. A linguagem utilizada pela personagem Cleycianne faz parte do vernáculo proveniente do discurso religioso e os comentários que faz dos fatos ocorridos vêm no sentido de moralizar comportamentos de acordo com a abstinência sexual e a procriação. Além 
disso, ela utiliza expressões interjetivas do universo cristão ao final de alguma mensagem, como, por exemplo, "Eta, God!", "3X Glória” ou “Amarrado em Cristo!".

Em resposta ao pronunciamento de Myrian Rios, o texto irônico "Cleycianne Demite"49 foi postado na sexta-feira, dia $1^{\circ}$ de julho de 2011 , e apresenta a personagem numa fotomontagem que parodia Donald Trump, âncora do programa Trainee (Aprendiz), reality-show da televisão norte-americana. "Cley Trump! Descontração em Cristo kkkkkkkkkkkkkkkk" é o subtítulo do texto. Nele, a modelo está com uma "vontade louca de contratar homossexuais aqui para trabalhar no blog e em minha casa só para poder demiti-los depois! Como isso dá muito trabalho, decidi transformar essa vontade minha em um quadro aqui no blog, de forma hepotética claro!".

A defesa da blogger se baseia na estratégia de contratação de homossexuais para depois demiti-los. O que sugere a interpretação, para além do direito aventado no discurso original, de prazer/poder baseados na defesa pela Palavra de Deus. Os discursos de Cleycianne e de Myrian Rios se aproximam um do outro, pois possuem a marca do discurso religioso. Entretanto, vale ressaltar que o perfil da modelo fotográfica cristã surge como estratégia de ironia ao discurso religioso com relação às questões sexuais.

Além disso, é possível notar certa constância na escrita de palavras com erros ortográficos nos textos de Cleycianne. Isto sugere que o sujeito que escreve ignora as normas cultas da escrita do português e torna possível compreender uma marca de estilização da personagem, ou seja, a demarcação da sua identidade. O texto de Cleycianne se faz pela dissimulação, pelo fingimento. A fala, ao invés de se opor ao texto original, ataca-o ironizando sua própria condição. Isso se dá pela seleção de ícones sexuais midiáticos (como Madonna, Reinaldo Gianechinni e Mulher Melancia). Ela promove um estranhamento de si, um descentramento e um mal-entendido, um desconcerto. Trata-se de uma situação crítica, pois leva esta ação ao limite de seus recursos e possibilidades. Leva à beira do abismo. Como diria Facioli: "A comunicação do irônico é crítica, pois sempre conduz a inteligibilidade de uma comunicação usual ao seu limite, deixando suspenso no ar uma boa soma do sentido que transita pela interlocução" (2010, p. 23).

http://www.cleycianne.com/2011/07/cleycianne-demite.html 
Tanto no texto irônico de Cley quanto, também, no vídeo de Myrian Réus as marcas de orientação sexual, de raça e de obesidade (corpo), como significados de diferença, dão direito às personagens de demitirem as pessoas. De outro modo, percebe-se a possibilidade de se pensar que se trata de uma marcação de diferença (identitária) e que convoca a pensar sobre as outras marcações que não as de orientação sexual. Ao defender para si a permissão/garantia de demitir uma funcionária obesa (blog da Cley e Myrian Réus; sendo que Cley elege a Mulher Melancia como exemplo de obesidade $=$ pecado), iguala quaisquer outras marcações à orientação sexual como elementos que dão direito ao empregador de efetuar a demissão. O texto irônico, nesse sentido, pode beirar o absurdo, pois por meio do que se é permitido se pode veicular o proibido; como o faz Cleycianne quando agradece a Deus por ter demitido pessoas em nome de Sua Palavra. Dessa forma, ela alia repugnância ao texto religioso.

No terceiro suporte, o site de microblogging Twitter, analisamos os tweets que participaram de uma das provas da \#GincanadaNonna. A \#GincanadaNonna é uma série de desafios em forma de provas propostos e realizados no ambiente online organizado pelo perfil do site @nairbello - falso perfil da famosa atriz e humorista brasileira Nair Bello, falecida em 2007, gerenciado por Gustavo Braun -, que geralmente dialogam com algum assunto recente veiculado pela mídia. Este caso se diferencia dos dois anteriores por ser uma produção colaborativa, ou seja, possui muitos autores e fomentadores (por meio de republicação e divulgação da gincana).

No caso em questão, foi proposto através de $t^{\text {weet }}{ }^{50}$ do perfil aos seus usuários seguidores a seguinte ação: "PROVA 2: A @myrianRios tem medo da babá pedófila e do motorista tarado. Sugira outras profissões que ela deveria temer. \#GincanaDaNonna". O tweet foi o disparador para que vários usuários criassem e veiculassem uma série de respostas ironizando o relato da deputada Myrian Rios. É importante notar que o autor fez menção ao perfil da deputada por meio do sistema de trackback do Twitter: colocando seu nome de usuário do site precedido de uma “@”. Assim, o usuário citado recebe em seu perfil, numa página especial, a mensagem que o referencia ${ }^{51}$.

Fica evidente, pois, o desejo de que a mesma recebesse os conteúdos,

50 http://twitter.com/\#!/nairbello/statuses/87973467240140801

51 Ao fazer isso, o texto se torna um link que ao ser acionado leva à página do usuário que foi referenciado. 
fato reforçado por outro tweet ${ }^{52}$ em que se incentiva que os usuários façam o mesmo - fazer conexão com o perfil da deputada.

Entre as respostas dadas, algumas referenciavam uma série de profissões: pipoqueiro, secretária, lutador, lixeiro, policial, funcionário do lar, médico, palhaço, professor, cozinheiro, narrador, segurança, açougueiro, dando-Ihes ora conotação sexual (como em “@myrianRios Tia, cuidado com o açougueiro homossexual, ele pode brincar com a linguiça antes de vender pra senhora \#GincanaDaNonna"), ora sentido de vingança pelo discurso proferido (como em “@myrianRios Cuidado com a Domestica Vingativa \#GincanaDaNonna") e ora sem uma referência mais explícita ao discurso, apenas em direção ao absurdo (como em “@nairbello O pipoqueiro da pracinha \#gincanadaNonna"). Ainda na lógica do absurdo e do nonsense algumas respostas trataram de personagens famosos de virais da internet, celebridades, personagens de novela e até seres do imaginário sobrenatural como duendes e marcianos. Outras respostas se referiam à situação de deputada ao citarem profissões ligadas à política, tais como deputados, vereadores, prefeitos e ministros, dando-Ihes uma conotação negativa (como em “@myrianRios Querida, vc deveria ter medo é dos seus colegas políticos! Esses são perigosos e traiçoeiros! \#GincanadaNonna”).

Algumas respostas iam ao encontro do passado de Rios, como seu casamento com o cantor Roberto Carlos, o fato de ter posado nua em revista masculina e a anterior profissão de atriz, geralmente associada à ideia de incompetência. Outras traziam profissões consideradas típicas de homossexuais, como cabeleireiro e caminhoneira, que estariam propensas a algum tipo de retaliação. Outras, ainda, atacavam os sacerdotes católicos, expondo a questão da pedofilia, geralmente atribuída a alguns deles, associando não só o fato de Rios ser católica e apresentadora de um canal televisivo dessa designação religiosa, mas também por seu discurso estar sustentado, em parte, em um viés religioso. Além disso, algumas pessoas questionavam a sanidade, a capacidade intelectual da referenciada e até sua estética. 


\section{Discussão e conclusão}

O fenômeno que analisamos se insere num momento histórico-político específico, sobre o qual dissertamos brevemente neste trabalho. Segundo Szaniecki, anteriormente a democracia, filha da modernidade, baseava-se em instituições que criavam uma representação - política e estética - de "povo", já que este não é nem uma entidade natural, nem empírica. Assim, o caráter múltiplo da população tornava-se identitário por meio dos mecanismos do "representar", reduzindo-a a uma unidade chamada "povo" (SZANIECKI, 2007). Entretanto, nos últimos anos, houve uma crise que tem impossibilitado a representação popular, uma vez que os espaços nacionais têm sido desestabilizados com o processo de globalização e de consolidação do poder de instituições supranacionais. Dessa forma, em termos políticos, o conceito de povo é superado pelo conceito de multidão. Cria-se a necessidade de pensar uma nova conceituação do corpo social criativo, uma vez que a multidão

desafia a representação política e estética porque é uma multiplicidade indefinida, incomensurável, incompatível com os "racionalismos teleológicos e transcendentais da modernidade". [...] Passamos de uma unidade representacional e transcendental abstrata para uma multiplicidade cooperativa e imanente concreta" (SZANIECKI, 2007, p. 110).

Assim, o poder baseado no discurso de uma maioria que governa dentro de uma razão monovalente, que não comporta a pluralidade da vida social, muitas vezes caindo na intolerância, como no discurso da deputada Myrian Rios, não faria sentido em uma sociedade democrática em que o "público" assume um caráter de exterioridade, afastado da vida.

A partir de Maffesoli (1997) podemos afirmar que quando o poder se torna indiferente, diluem-se as classes em pequenos corpos sociais, como, neste caso, homossexuais e simpatizantes das causas das minorias sexuais e, dessa forma, descola-se de todos os procedimentos de representação, tornando-se a base da ruptura entre o poder e a sociedade. Assim, destacando o papel importante da paixão nas lutas políticas, esses embates que surgem dessas diferenças (agentes do poder e pequenos corpos sociais) 
geram conflitos que nem sempre se expressam de forma violenta contra o poder estabelecido, mas podem assumir várias características: indiferença para com a coisa pública, astúcia, ironia, inércia, resistência silenciosa, abstenção, brincadeira escancarada, inversão carnavalesca etc. com o instinto de conservação e luta dos direitos do grupo (MAFFESOLI, 1997).

Atualmente, com o crescimento e o fato de ocuparem cada vez mais posição de destaque como forma de interação e de fonte de informação, as redes sociais online têm se tornado elementos marcantes na influência da formação da opinião pública. Ora, se a atividade política está absolutamente mergulhada na opinião pública, já que dela depende para receber o apoio das multidões, não é possível imaginar um processo político que não tenha sua valoração - positiva ou negativa - junto ao público sem o destaque das ações de seus agentes. Assim, as áreas de conexão entre política e comunicação, ao mesmo tempo complementares e conflituosas, "ao se (re)adequarem à nova circunstância de ambiente configurada pela mídia, possibilitam a emergência de novas configurações da política" (RUBIM, 2000, p. 46).

Nesse sentido, podemos supor que os discursos interferem politicamente ao trazer à tona os argumentos implícitos na ironia do autor, de maneira dialógica ou intersubjetiva (BRAIT, 1996; HUTCHEON, 2000), o que significa exigir que o interlocutor se posicione de um determinado modo para que ela se concretize. Isso faz da ironia, se não uma boa estratégia de convencimento, pelo menos uma maneira de seu enunciador divulgar suas ideologias e crenças. Percebe-se que a contradição que há no enunciado não é de expressões em si, mas de valor argumentativo que só poderia ser tido como contrário se os receptores das mensagens tivessem, com o autor, um quadro de valores de referência comum. Ou seja, o discurso irônico exige uma interação de conhecimentos comuns entre os seus sujeitos, tanto na instância de produção quanto na de recepção.

No caso do nosso trabalho, constatamos duas grandes estratégias nas ironias dos discursos pesquisados: uma procurava desacreditar a deputada atacando-a em seu passado de vida pública (ex-atriz, divorciada do cantor Roberto Carlos, ter posado nua), sua crença (ser atualmente católica e apresentadora de programa religioso) e suas capacidades físico-mentais; e outra visava desmontar os argumentos de seu discurso (baseado em cren- 
ças religiosas e em preconceitos trabalhistas por questão de sexo).

Dessa maneira, as personagens locutoras dos enunciados estudados que carregam o discurso sério de seus enunciadores em alguns casos se travestem de caricaturas de aspectos da deputada, superlativando-os e para impor-Ihe outras características. Em outros, tomam caráter de sarcasmo, fazendo críticas mais efetivas e diretas. Sobre o assunto, Brait (1997, p. 130) diz que na ironia o autor fala a linguagem do outro, "porém, reveste essa linguagem de orientação oposta a do outro. É uma espécie de emprego ambíguo do discurso do outro". No caso presente, a ironia põe as palavras voltando-se para o objeto do discurso como palavra comum a ele, ao mesmo tempo em que se volta para um outro discurso, implicando o reconhecimento do segundo contexto. Logo, o discurso torna-se um palco de luta entre duas vozes: a segunda voz, sendo instalada no discurso do outro, entrando em hostilidade com o seu agente primitivo e obrigando-o a servir a fins opostos, revelando uma pluralidade de vozes orientadas na contradição (BRAIT, 1997).

Como observadas, as estratégias utilizadas pelos enunciadores dos argumentos irônicos foram no sentido de desacreditar a enunciadora do texto original, além de questionar a validade de seus argumentos. Para isso, tomam os elementos do discurso original com a finalidade de criar outro para fins contrários a ele, descreditando-o e trazendo o embate de ambos dentro de si. Nesse aspecto, num contexto histórico-político em que cada vez mais cresce a importância das redes sociais online na influência da opinião pública e a força da opinião pública sobre o fazer político, além do exposto ao longo do trabalho sobre a figura da ironia, fica evidente a eficácia iconoclasta desse recurso na corrosão do relato proferido por aquele cuja ideologia política é oposta à do irônico. Vale lembrar que a necessidade de compartilhamento de contextos entre os interlocutores, entretanto, coloca em risco a eficácia desse recurso estilístico como estratégia argumentativa e como forma de apoio e resistência numa ótica política.

\section{Referências}

BRAIT, B. Ironia em perspectiva polifônica. Campinas: Unicamp, 1996. CRESWELL, J. W. Projeto de pesquisa: métodos qualitativo, quantitativo e 
misto. São Paulo: Artmed, 2007

DEBORD, G. A sociedade do espetáculo. Rio de Janeiro: Contraponto, 1997.

DELEUZE, G. Conversações. Rio de Janeiro: Ed. 34, 1992.

DELEUZE, G.; GUATTARI, F. Mil platôs: capitalismo e esquizofrenia. São Paulo: Editora 34, 2004. vol. 1.

FACIOLI, A. A ironia: considerações filosóficas e psicológicas. Curitiba: Juruá, 2010.

FISCHER, R. M. B. Foucault e a análise do discurso em educação. Cadernos de Pesquisa, n. 114, p. 197-223, nov. 2001. Disponível em <http://www. scielo.br/pdf/cp/n114/a09n114.pdf>. Acesso em: 24 jul 2011.

HARAWAY, D. J. Antropologia do Ciborgue: as vertigens do pós-humano. Organização e tradução de Tomaz Tadeu. 2. ed. Belo Horizonte: Autêntica Editora, 2009.

HARDT, M.; NEGRI, A. Império. Rio de Janeiro: Record, 2001.

HARDT, M.; NEGRI, A. Multidão. Rio de Janeiro: Record, 2005.

HUTCHEON, L. Teoria e política da ironia. Belo Horizonte: UFMG, 2000.

LEVY, P. Cibercultura. São Paulo: Editora 34, 1999.

MAFFESOLI, M. A transfiguração do político: a tribalização do mundo. Porto Alegre: Sulina, 1997.

NASCIMENTO, S. M. B. N. A ironia como estratégia argumentativa em texto de crítica política da internet. Entretextos, Londrina, v. 10, n. 1, p. 8-33, jan./ jun. 2010.

RUBIM, A. A. C. Comunicação \& Política. São Paulo: Hacker, 2000.

SANTAELLA, L. Culturas e Artes do Pós-Humano: Da Cultura das Mídias à Cibercultura. São Paulo: Paulus, 2008.

ZANIECK, B. Estéticas da Multidão. Rio de Janeiro: Civilização Brasileira, 2007. 